\title{
A Computational Architecture for Learning Objects Authoring and Personalization in Ubiquitous Learning Environments
}

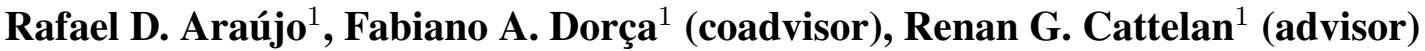 \\ ${ }^{1}$ Faculdade de Computação - Universidade Federal de Uberlândia \\ Uberlândia/MG, Brasil \\ \{rafael.araujo, fabianodor, renan\}@ufu.br
}

\begin{abstract}
Computers have become everyday tools in the contemporary classroom to support both instructors and students in the learning process. Ubiquitous Learning Environments (ULEs) are created to combine real and virtual learning environments in order to produce richer study artifacts composed multimedia documents structured as Learning Objects (LOs). This work presents a computational architecture grounded on ULEs and Intelligent Tutoring Systems concepts, capable of structuring LOs captured in classrooms and their metadata through a collaborative approach, and offering content personalization and recommendation features to students. The resulting $L O$ repository, with metadata in the IEEE-LOM format, is made publicly available.
\end{abstract}

Resumo. Os computadores se tornaram ferramentas cotidianas nas salas de aulas contemporâneas e apoiam tanto professores quanto estudantes no processo de ensino e aprendizagem. Ambientes Educacionais Ubíquos (AEUs) combinam ambientes reais e virtuais de aprendizagem visando produzir artefatos de estudo mais ricos, na forma de documentos multimídia estruturados como Objetos de Aprendizagem (OAs). Este trabalho apresenta uma arquitetura computacional, fundamentada nos conceitos de AEUs e de Sistemas Tutores Inteligentes, capaz de estruturar OAs capturados em salas de aula e seus metadados utilizando uma abordagem colaborativa e também personalizar e recomendar conteúdo aos estudantes. O repositório de OAs resultante, com metadados no formato IEEE-LOM, é disponibilizado publicamente.

\section{Introduction}

Ubiquitous Learning Environments (ULEs) are created to combine real and virtual learning environments in order to produce richer study artifacts [Zhao and Okamoto 2011]. Classrooms equipped with computational devices produce artifacts that can reconstruct the captured experiences for later use and review, preventing users from losing any important point while making notes, for example. Thus, a large volume of digital content is generated in different formats and must be retrieved and presented in a clear way, mainly to comply with the user's needs, which becomes a challenge for information retrieval systems. Such content may be useless if appropriate means for reaching and visualizing it are not provided to users. Adaptive Educational Hypermedia (AEH) comes to meet each student needs, adapting the content to his/her objectives, knowledge level, personal interests, preferences, and learning styles, avoiding the "one-size-fits-all" approach in the educational field. 
At the same time, the concept of Learning Object (LO) has emerged to minimize the time and effort spent for developing reusable educational content. LOs are important assets to restructure traditional pedagogical practices [Wiley 2000]. Nevertheless, LO authoring remains a difficult task, both in terms of design and preparation of the content itself, as well as the process of obtaining and filling out their associated metadata, which is needed to organize, classify and effectively further reuse them. In this way, we face the challenge of taking advantage of the nature of ULEs - which becomes an intrinsic factory of LOs - to generate structured LOs and, concomitantly, presenting them in an organized way, with intuitive interfaces, to assist students in their learning process and to facilitate their interaction with instructors.

The main goal of this research project is to design and evaluate a computational architecture for adaptive hypermedia applications in ubiquitous learning environments in order to tackle the complex problem of individualized learning. Such architecture should be grounded on ULEs, AEH and Intelligent Tutoring Systems (ITSs) concepts and support multimedia content recommendation and personalization by means of specialized modules that combine cognitive, social, collaborative, and contextual aspects. Its evaluation aims at answering the following research questions:

- Q1: Can ULEs provide support for automatic creation of structured LOs?

- Q1.1: Which kind of information can be extracted from those environments in order to classify LOs according to students' learning styles?

- Q2: How does content adaptation based on learning styles affect student performance in ULEs?

- Q2.1: Do students notice that content is being personalized in such environments?

The remainder of this paper is organized as follows: related work is presented in Section 2; the proposed approach is detailed in Section 3; evaluations are discussed in Section 4; and, finally, conclusions are presented in Section 5.

\section{Related Work}

Youubi [Monteiro et al. 2017] is a ULE designed as a component-oriented architecture and accessible through mobile, web, smartwatch and iDTV platforms. It is a platform that provides support for formal and informal learning by means of contextual, social, and gamification features. Their architecture focuses on recommendations for elementary entities, such as Person, Location, Event, Challenge, and Group. The approach proposed here focuses on personalized and individual content adaptation as well as LOs authoring structured according to the IEEE-LOM standard.

The Generalized Intelligent Framework for Tutoring (GIFT) [Sottilare et al. 2017] is an adaptive tutoring architecture that includes a myriad of features, such as authoring tools, learner model, sensor processing module, pedagogical module, among others. Some differences from this work may be pointed out. As we noticed, GIFT does not consider either refinement nor collaborative content enrichment. Also, it does not consider the CLEO extensions and does not provide a way to classify LOs according to LS.

GlobalEdu [Barbosa et al. 2013] is a ubiquitous learning architecture that explores the concept of LO, also represented in the IEEE-LOM standard, to explore pedagogical opportunities in a context-aware environment. Their approach matches learners with similar or complementary interest to stimulate their interaction. Although GlobalEdu also 
adapts LOs according to students' LS, the CLEO extensions are not considered and, as far as we know, there is no collaborative feature for content enrichment.

[Vidal et al. 2016] proposed an adaptive hypermedia-based approach for assisting students to accomplish their activities in Accounting courses. Their approach takes into consideration a domain model, representing accounting knowledge, a student model that considers static and dynamic information, and an adaptive model which provides an adaptive navigation mechanism based on student model. However, the latter does not consider LS for adaptation neither proposes an approach for supporting LO authoring.

Most studies found in the literature are focused on some of the key aspects proposed in this research: context-awareness, collaboration/social interactions, and cognitive profile. In addition, the concept of LO along with standard metadata representation is not always explored, nor its enrichment and refinement. Moreover, this research aims at using information produced by ULEs to make the adaptive web-based educational systems richer, which highlights its contribution to the area.

\section{AULA: Adaptive and Ubiquitous Learning Architecture}

The proposed architecture design follows the four phases proposed by [Abowd et al. 1996]. First, in the pre-production phase, instructors prepare their lectures before going to the classroom. Then, different computing devices scattered into the environment record them during the live recording phase. In the post-production phase, all media streams are synchronized and stored. Once recorded and stored, each lecture becomes available for students in the access phase, where content can be presented in a personalized way. Additionally, students and instructors can enrich the original content in a fifth one, extension phase [Pimentel et al. 2001].

The Adaptive and Ubiquitous Learning Architecture (AULA) comprises some specialized modules, shown in Figure 1, in which each individual involved in the teaching/learning process plays a key role to create the learning experience together. The architecture provides support for contextual, collaborative, social, and cognitive features. Many of its components provides interfaces that allow communication through HyperText Transfer Protocol (HTTP) requests.

\subsection{Learning Objects Authoring}

Consistent LOs (content itself and metadata) provide meaningful information that may be used to create personalized experiences with educational content according to students' preferences and their individual differences. Yet, it is still an arduous and time-consuming task. Lectures recorded in ULEs can be regarded as LOs since they are pieces of educational content. However, these LOs are coarse-grained as they represent a whole lecture, which is typically more than 1-hour long.

Therefore, one more step was included in the LO creation process to refine them through collaborative features. Each lecture consists of a set of slides that can be grouped into different subjects, or topics. Knowing that, a single lecture generates many other LOs, which have been structured in three hierarchical levels: lecture, subject, and slide. A lecture consists of several subjects, which are composed of several slides [Araújo et al. 2016a]. As an example, imagine a lecture to teach repetition structures in the context of computer programming. First, it could have a set of introductory content 
VII Congresso Brasileiro de Informática na Educação (CBIE 2018)

Anais dos Workshops do VII Congresso Brasileiro de Informática na Educação (WCBIE 2018)

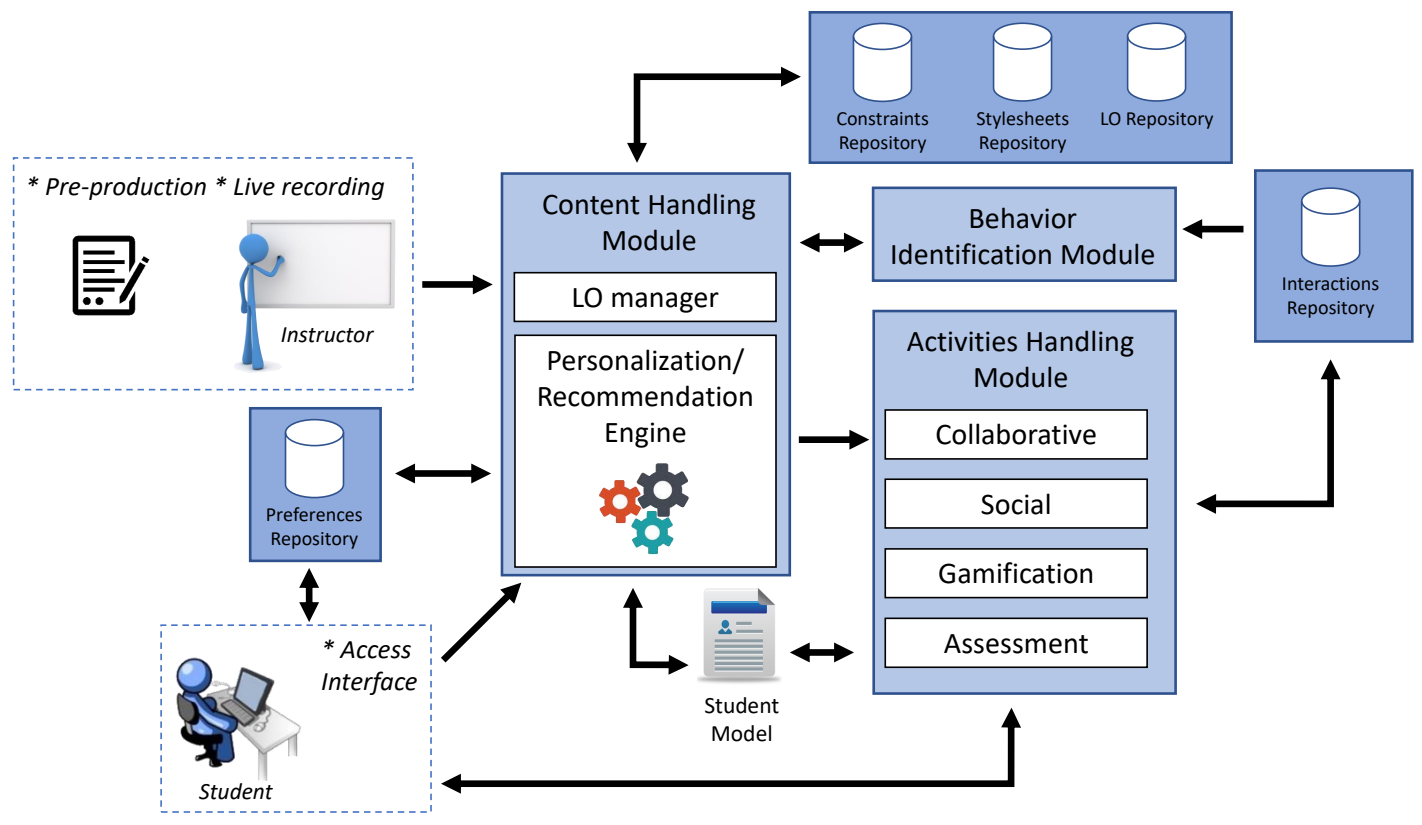

Figure 1. Architecture Overview [Araújo et al. 2017b].

(such as lecture's title and goal, and agenda). Then, the content could be divided, for example, into different subject matters, such as "For Loops", "While Loops", "Do While Loops", among others. Each subject may be presented through different learning resources, such as textual or visual definition, example, simulation, etc. Finally, the lecture could have a set of concluding content that includes the lecture's summary and references.

During the access phase, students and instructors are allowed to label subjects within a lecture using the bookmarking feature. They can indicate in which slide a new subject begins and label it with a title. Bookmarks are used to split the lecture into smaller LOs. Each labeled subject becomes a new LO internally, and the most common labels are presented to other students. Figure 2 shows an example of a captured lecture with a bookmark represented by bullet (1). Additionally, users can also collaboratively inform the resource types of that the slide, as shown by bullet (2).

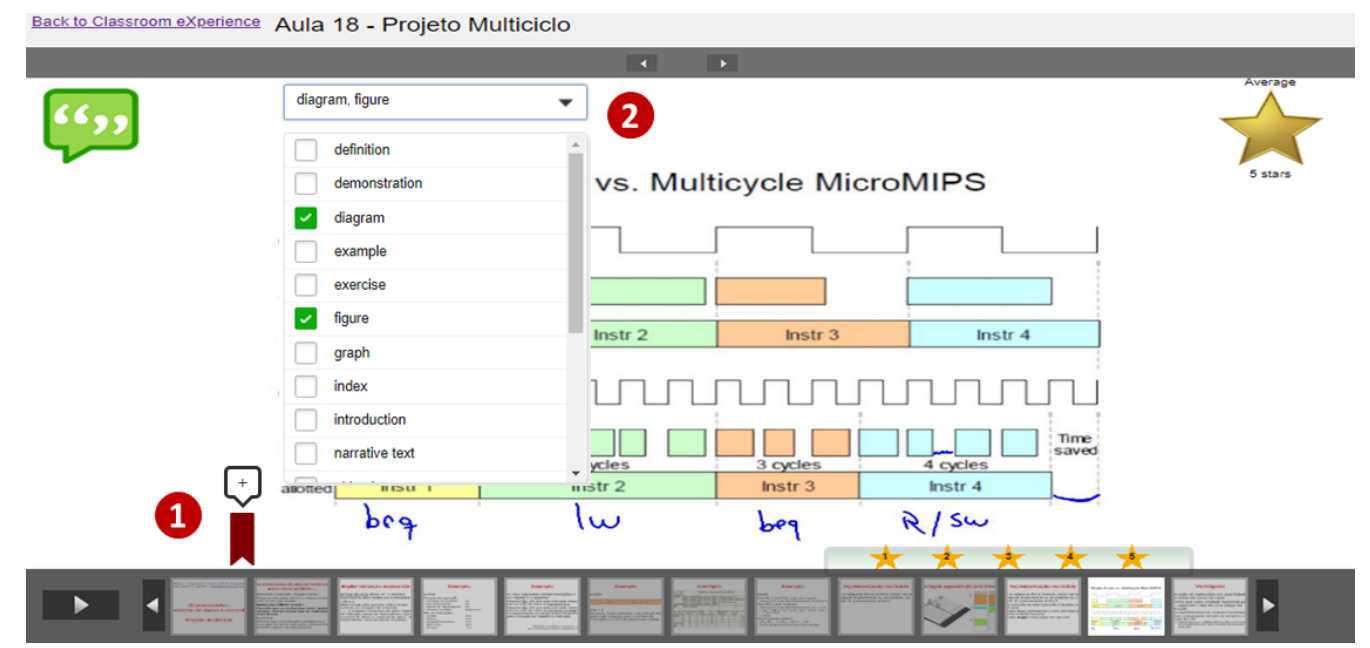

Figure 2. Visualization of a captured lecture using $\mathbf{C X}$.

In this work, we use the IEEE Learning Object Metadata (IEEE-LOM) standard 
[IEEE 2002] as a base schema to represent the LO metadata, since it is the most widely used in the domain of learning and education [Friesen 2004]. However, the vocabulary for the "Learning Resource Type" field includes some other values with higher semantic meanings proposed by CLEO extensions [CLEO 2003]. Nonetheless, the reuse property is maintained. Further, the proposed architecture also plays a role as an LO producer, not only a consumer, it means that it does not depend on finding LOs in external repositories.

Social features contribute to create a more interactive environment as well as to enrich content. A multimedia content enrichment model that fosters hierarchical digital artifacts construction has been implemented into the CX platform in the extension phase [Araújo et al. 2017a]. Slides rating and comments used to ask questions or pointing out important issues while accessing the captured content are some of those features. Comments are eligible for replies and rating, which encourage debate and assess relevance.

The proposed architecture also takes into account the need of additional content, such as videos and quizzes. Quizzes, or multiple-choice questions, can be created inside a recorded lecture and they are associated with a slide, so students can answer them while reviewing the lecture. Videos are external content that complement the what is presented in a specific slide. As CX turned out to be a factory of LOs, we decided to create a public repository of LOs, called CX-LOR ${ }^{1}$, freely available to the research community.

\subsection{Content Personalization}

Once defined both the content type and the way that users are represented, it is possible to design algorithms and rules to fit the content according to users' needs. The first level of personalization occurs based on users' access context in which presentation rules define the best way to present the content. For example, if the user accesses the content using a device with a low screen resolution, it is better to present a textual content rather than detailed slides. This kind of rules is used to create a ranking of stylesheets; however, the user is free to choose no matter which one.

The second level of personalization occurs inside a lecture based on the output of the "Behavior Identification Module". Inside a lecture, the personalization occurs based on the student model and LOs' characteristics. As a case study, an approach based on Learning Styles (LS) was implemented for validating the architecture. Basically, since each lecture is an ensemble of LOs, the lecture could be reordered and assembled according to the LS of each student. There are studies claiming positive impacts on learning outcomes [Alshammari et al. 2015, El-Bishouty et al. 2014]. On the other hand, there have been studies that disagree with its efficacy [Kirschner 2017, An and Carr 2017]. However, criticism usually happens because many LS models have binary classifications, without considering uncertainties (also because many studies consider the presentation of a single type of content based on LS).

Students' characteristics are stored in a Student Model (SM) that uses a probabilistic approach proposed by [Dorça et al. 2013] indicating that an LS is not fixed and can evolve over time. This approach, which is based on the widely used Felder and Silverman Learning Style Model (FSLSM) [Felder and Silverman 1988], stores eight numeric values representing the tendency of preference for one of the LS dimensions. It is important to note that this information can be updated using static or dynamic approaches. In

${ }^{1}$ http: //cx.facom.ufu.br/cxlor 
static approaches, those values are initialized only once, usually when the student enrolls in the course. In dynamic approaches, those values are not only initialized but updated over time, representing changing of preferences. In this work, each LS is initialized with a 50\% value and updated through the answering of the Index of Learning Styles (ILS) in a distributed way among login sessions during the semester to prevent students from getting tired and demotivated given the size of the entire questionnaire (44 questions). Additionally, each answered question gives some points to the gamification module as a way to motivate students to answer them.

Consider a set of rules that maps out a subset of IEEE-LOM fields to LS of the FSLSM to represent the probability (or tendency) of the respective LO being matched with each LS [Dorça et al. 2016]. Let $o$ be an LO, $P$ be the proportionality of rules satisfied by $o$ considering a specific learning style dimension, and $L S$ be the probability stored in the student model for each LS dimension. The relevance $R$ for an LO $o$ is given by Eq. (1), as the sum of values obtained by $o$ in each of the eight LS [Araújo et al. 2018].

$$
R(o)=\sum_{i=1}^{8}\left(P_{i} \times L S_{i}\right)
$$

Using this computation, LOs that compose the captured lecture may be internally rearranged within topics to consider individual LS. In this way, the same lecture could be personalized to each student based on the ranking of LOs. Other approaches could be implemented here to compute the relevance of LOs to each student.

\section{Evaluation}

Different experiments were performed in order to check the feasibility of the proposed architecture. A qualitative analysis was used to find answers for research questions Q1 and Q1.1, while the research questions Q2 and Q2.1 were answered using both quantitative and qualitative analyzes. The first experiment aimed at evaluating how ULEs can support the LOs authoring process and the use of a collaborative bookmarking approach to refine them. In total, 30 students participated in this study. Also, three experts in the Human-Computer Interaction (HCI) field evaluated the quality of the generated metadata for the LOs of an HCI course. This experiment was divided in four phases: (I) Creating bookmarks, (II) Evaluating bookmarks, (III) Redefining bookmarks, and (IV) Experts evaluation. Nine graduate students participated in the phase I. Phases II and III counted on 21 undergraduate students and the last phase (IV) included three HCI experts.

In general, the average response remained above the central point of the scale, which suggests that participants were more likely to agree with the presented affirmatives, showing that the presented approach was well received by students. The lowest reviews in both phases indicated that students might not be totally willing to create bookmarks for all captured lectures. However, users do not need to create bookmarks for all of them since the proposed approach has a collaborative nature, so the LO structure is built as users create and share as many bookmarks as they wish. In total, 21 students also evaluated the quality, utility, and usability of the created bookmarks [Araújo et al. 2014, Araújo et al. 2016b, Araújo et al. 2016a].

The LO personalization was first evaluated in some preliminary exploratory analysis using simulated data - for both LO and students - to check the ranking of LOs accor- 
VII Congresso Brasileiro de Informática na Educação (CBIE 2018)

Anais dos Workshops do VII Congresso Brasileiro de Informática na Educação (WCBIE 2018)

ding to students' LS [Dorça et al. 2016]. Then, some adjustments were made on the base of rules that compute the relevance of LOs for each student and this approach was implemented a real-world system used as an educational complementary tool, called Classroom eXperience $(\mathrm{CX})$, to validate it in real settings.

Experiments with 115 undergraduate students from four different courses (Computer Organization and Architecture, Human-Computer Interaction, Mathematical Logic, and Software Engineering) were conducted using the CX platform. Pre and post tests were also administered. After collecting data, some statistical analyses were performed. First, students' LS were discussed and analyzed regarding the distribution of different interactions with the system among different LS. In addition, the effects of the personalization approach on students' grades in this context were explored as well as the relationship between grades and different activities performed in the system. Also, students of all courses answered a subjective questionnaire at the end of the course to evaluate their perception about utility and usability of the platform and their own study behavior.

The behavior of groups of students with different LS was explored by using a datadriven approach. Since our SM implements a probabilistic approach for LS, each student does not have an explicit LS classification. In this way, 5 ranges of LS values were defined to classify students into groups of LS preference (strong preference and balanced preference for one side of the dimension, similarly for the opposite side, and no preference) to be able to check the distribution of interactions in each group. The distribution of login sessions, collaboration activities, and quiz answering within each LS dimension (with five LS classifications) was tested using the Kruskal-Wallis H test, which is used to compare three or more independent samples. It assumes that the samples come from identical populations (null hypothesis). This test is a non-parametric method that was chosen because it does not assume a normal distribution of the residuals. Processing, Perception and Input dimensions showed statistically significant results, indicating to reject the null hypothesis of the test. However, it does not show exactly where the difference lies. In this way, pairwise comparisons between groups were performed.

Results have shown that Active-Balanced students answered much more quizzes (Median=12.5) than Balanced students (Median=0). Similarly, Sensing-Balanced students also answered much more quizzes (Median=24) than Balanced students (Median=0). It is interesting to note that statistically significant differences were not found between opposite LS of the same dimension. Additionally, periods with and without personalized content were evaluated through students' grades obtained on the exams for each specific period using the Wilcoxon signed-rank test, which is a non-parametric statistical hypothesis test used to compare two related samples. In this case, the samples are composed by the grades representing repeated measures for the same individual. Also, the grades obtained on the exam carried out in the period with content personalization were statistically higher than the grades obtained on the exam carried out in the period without content personalization for two courses, Computer Organization and Architecture $(Z=-2.745 ; p<0.01)$ and Software Engineering $(Z=-2.677 ; p<0.01)$. If we look at the median values, the period with content personalization had a median grade around 20\% higher than the other period. On the other hand, in the Human-Computer Interaction course, the results showed the opposite scenario with lower grades during the the period with content personalization $(Z=-2.663 ; p<0.01)$. For the Mathematical 
VII Congresso Brasileiro de Informática na Educação (CBIE 2018)

Anais dos Workshops do VII Congresso Brasileiro de Informática na Educação (WCBIE 2018)

Logic course, there was no statistically significant difference on the scores. We argue that the design of each course (and the availability of different resource types) may impact students' performance depending on the profile of the enrolled students.

The Spearman's rank correlation coefficient $(\rho)$ was computed to check if there are relationships between grades and variables related to system interactions (Table 1). Positive low correlations were found between the final grade and the following variables: the number of opened lectures in the whole semester, total of collaborative activities performed in the system, the amount of answered quizzes as well as the number of answered quizzes per login session. The final grade and relative gain presented a positive and moderate correlation with the amount of login sessions during the entire semester, both statistically significant at the 0.01 level. It means that students who accessed more the platform scored better on exams, which may have also been influenced by the amount of proactive activities performed (answered quizzes and collaborative activities).

Table 1. Correlations between final grades and interactions with the system.

\begin{tabular}{lccccc}
\hline Statistics & LOGIN & LECTOPEN & COLAB & QUIZANSWER & QUIZLOGIN \\
\hline Spearman's $\rho$ & $0.374 * *$ & $0.233^{*}$ & $0.217 *$ & $0.284 * *$ & $0.262^{*}$ \\
Sig. (2-tailed) & 0.000 & 0.023 & 0.034 & 0.005 & 0.010 \\
$\mathrm{~N}$ & 95 & 95 & 95 & 95 & 95 \\
\hline
\end{tabular}

LOGIN: amount of login sessions; LECTOPEN: number of opened lectures; COLAB: total of collab. activities; QUIZANSWER: amount of answered quizzes; QUIZLOGIN: number of answered quizzes per login session; * and **: significant correlations at the 0.05 level and the 0.01 level (2-tailed), respectively.

\section{Conclusion}

This doctoral study proposed a computational architecture, named AULA, that blends the concepts of ULEs, AEH and ITSs to generate structured LOs and present them in a personalized way to students, which complies with the main goal of this work. Also, it aims at facilitating the interaction between instructors and students outside the classroom.

Experiments in real world scenarios included 115 undergraduate students enrolled in four different courses related to Computer Science majors. Pretest and posttest assessments were administered as well as a usability questionnaire. Results showed that partial grades obtained on the exam carried out in the period with content personalization based on LS were statistically higher $(\approx 20 \%)$ than the grades obtained during the period without content personalization in two of four courses.

As observed, such tools have the potential to change the traditional paradigm of teaching, in which the instructor is the only entity to provide content, to a scenario where students have a more active role in the production of knowledge. In addition, social and collaborative features allow for the enrichment of content and provide input to intelligent techniques for tailoring content to users' needs. Results have shown that students who accessed more the platform have scored better on exams, which may have also been influenced by the amount of proactive activities performed.

The following contributions result from this thesis: $(i)$ design of a computational architecture for adaptive hypermedia applications that takes into account contextual, social, collaborative and cognitive information in order to recommend and personalize educational content; (ii) relationship mapping between the CLEO vocabulary extension 
VII Congresso Brasileiro de Informática na Educação (CBIE 2018)

Anais dos Workshops do VII Congresso Brasileiro de Informática na Educação (WCBIE 2018)

for the "Learning Resource Type" field of the IEEE-LOM standard and the FSLSM; (iii) implementation and evaluation of the proposed approach in real settings and with real users; (iv) creation of CX-LOR, a publicly available repository of LOs; (v) establishment of research collaboration with the Personalized Adaptive Web Systems Lab of the University of Pittsburgh, headed by Dr. Peter Brusilovsky.

\section{Acknowledgments}

The authors acknowledge the support of CNPq, FAPEMIG, FACOM/PROPP/UFU, and PET/MEC/SESu. This study was financed in part by the Coordenação de Aperfeiçoamento de Pessoal de Nível Superior - Brasil (CAPES) - Finance Code 001.

\section{References}

Abowd, G. D., Atkeson, C. G., Feinstein, A., Hmelo, C., Kooper, R., Long, S., Sawhney, N., and Tani, M. (1996). Teaching and Learning as Multimedia Authoring: The Classroom 2000 Project. In Proc. of Multimedia '96, pages 187-198.

Alshammari, M., Anane, R., and Hendley, R. J. (2015). The impact of learning style adaptivity in teaching computer security. In Proc. of ACM ITiCSE'15, pages 135-140.

An, D. and Carr, M. (2017). Learning styles theory fails to explain learning and achievement: Recommendations for alternative approaches. PERS INDIV DIFFER, 116:410416.

Araújo, R., Brant-Ribeiro, T., de Freitas, R., Dorça, F., and Cattelan, R. (2014). Autoria automática de objetos de aprendizagem a partir de captura multimídia e associação a estilos de aprendizagem. In Proc. of the XXV SBIE, pages 229-238.

Araújo, R., Brant-Ribeiro, T., Ferreira, H., Dorça, F., and Cattelan, R. (2016a). Segmentação Colaborativa de Objetos de Aprendizagem Utilizando Bookmarks em Ambientes Educacionais Ubíquos. In Proc. of the XXVII SBIE, pages 1205-1214.

Araújo, R., Brant-Ribeiro, T., Mendonça, I., Mendes, M., Dorça, F., and Cattelan, R. (2017a). Social and Collaborative Interactions for Educational Content Enrichment in ULEs. EDUC TECHNOL SOC, 20(3):133-144.

Araújo, R., Dorça, F., and Cattelan, R. (2017b). Towards an Adaptive and Ubiquitous Learning Architecture. In Proc. of IEEE ICALT' 17, pages 539-541.

Araújo, R., Ferreira, H., Dorça, F., and Cattelan, R. (2016b). Learning Objects Authoring Supported by Ubiquitous Learning Environments. In Companion Pub. of IUI '16, pages 49-53.

Araújo, R., Ferreira, H., Dorça, F., and Cattelan, R. (2018). A Hybrid Architecture for Adaptive, Intelligent and Ubiquitous Educational Systems. In Zheng, R., editor, Digital Technologies and Instructional Design for Personalized Learning, Chapter 6, pages 120-144. IGI Global.

Barbosa, D. N. F., Barbosa, J. L. V., Bassani, P. B. S., Rosa, J. a., Martins, M., and Nino, C. (2013). Content Management in a Ubiquitous Learning Environment. INT J COMPUT APPL T, 46(1):24-35.

CLEO (2003). CLEO Extensions to the IEEE Learning Object Metadata. Technical report, CLEO Collaborative Partners (Cisco Systems, Inc., IBM Corporation, Microsoft Corporation, Thomson NETg). Available on https://www.oasis-open. 
VII Congresso Brasileiro de Informática na Educação (CBIE 2018)

Anais dos Workshops do VII Congresso Brasileiro de Informática na Educação (WCBIE 2018)

org/committees/download.php/20490/CLEO_LOM_Ext_v1dla.pdf. Accessed in: October, 2016.

Dorça, F., Araújo, R., de Carvalho, V., Resende, D., and Cattelan, R. (2016). An Automatic and Dynamic Approach for Personalized Recommendation of Learning Objects Considering Students Learning Styles: An Experimental Analysis. Informatics in Education, 15(1):45-62.

Dorça, F., Lima, L., Fernandes, M., and Lopes, C. (2013). Comparing strategies for modeling students learning styles through reinforcement learning in adaptive and intelligent educational systems: An experimental analysis. EXPERT SYST APPL, 40(6):20922101.

El-Bishouty, M. M., Chang, T.-W., Graf, S., Kinshuk, and Chen, N.-S. (2014). Smart e-course recommender based on learning styles. Journal of Computers in Education, 1(1):99-111.

Felder, R. M. and Silverman, L. K. (1988). Learning and Teaching Styles in Engineering Education. J ENG EDUC, 78(7):674-681.

Friesen, N. (2004). The International Learning Object Metadata Survey. INT REV RES OPEN DIS, 5(3).

IEEE (2002). LTSC 1484.12.1, Draft Standard for Learning Object Metadata. Learning Technology Standards Committee of the IEEE.

Kirschner, P. A. (2017). Stop propagating the learning styles myth. COMPUT EDUC, 106:166-171.

Monteiro, B. d. S., Oliveira, E. d., Gomes, A. S., and Mendes Neto, F. M. (2017). Youubi: Ubiquitous Learning Environment. RBIE, 25(01):94-113.

Pimentel, M. d. G., Ishiguro, Y., Kerimbaev, B., Abowd, G. D., and Guzdial, M. (2001). Supporting Educational Activities through Dynamic Web Interfaces. INTERACT COMPUT, 13(3):353-374.

Sottilare, R. A., Brawner, K. W., Sinatra, A. M., and Johnston, J. H. (2017). An Updated Concept for a Generalized Intelligent Framework for Tutoring (GIFT). Technical report, U.S. ARL-HRED, Orlando, USA. Available on: https: / / gifttutoring . org. Accessed in: October, 2017.

Vidal, I. M. G., Costa, E. d. B., Silva, L. D. d., Araújo, F. F. d., and Ferreira, R. (2016). A Hypermedia-based Adaptive Educational System for Assisting Students in Systems and Information Technology Domain for Accountability, pages 277-286. Springer International Publishing, Cham.

Wiley, D. A. (2000). Connecting learning objects to instructional design theory: A definition, a metaphor, and a taxonomy. Available on http://reusability.org/ read/chapters/wiley.doc. Accessed: in May 10th, 2016.

Zhao, X. and Okamoto, T. (2011). Adaptive multimedia content delivery for contextaware u-learning. International Journal of Mobile Learning and Organisation, 5(1):46-63. 